\title{
Adherence to quality breast cancer survivorship care in four Canadian provinces: a CanIMPACT retrospective cohort study
}

Mary L. McBride ${ }^{1,2^{*}}$ (D, Patti A. Groome $3^{3,4,5}$, Kathleen Decker ${ }^{6,7}$, Cynthia Kendell $^{8}$, Li Jiang ${ }^{5,9}$, Marlo Whitehead ${ }^{5}$, Dongdong Li ${ }^{1}$, Eva Grunfeld ${ }^{5,10,11,12}$ and for the CanIMPACT Team

\begin{abstract}
Background: In order to maximize later health, there are established components and guidelines for quality followup care of breast cancer survivors. However, adherence to quality follow-up in Canada may not be optimal, and may vary by province. We determined and compared the proportion of patients in each province who received adherent and non-adherent surveillance for recurrence, new cancers and late effects, recommended preventive care, and recommended physician visits for comorbidities.

Methods: Cohorts consisted of all adult women diagnosed with incident invasive breast cancer between 2007 and 2010/2012 in four Canadian provinces (British Columbia (BC) N=9338; Manitoba N=2688; Ontario N=23,700; Nova Scotia (NS) $N=2735$ ), identified from provincial cancer registries, alive and cancer-free at 30 months post-diagnosis. Their healthcare utilization was determined from one to 5 years post-treatment, using linked administrative databases. Adherence, underuse, and overuse of recommended services were evaluated yearly and compared using descriptive statistics.

Results: In all provinces and follow-up years, the majority of survivors had more than the recommended number of visits to either an oncologist or primary care physician (range 53.8\% NS Year 3; 85.8\% Ontario Year 4). The proportion of patients with the guideline-recommended number of oncologist visits varied by province (range $29.8 \%$ BC Year 5; 74.8\% Ontario Year 5), and the proportion of patients with less than the recommended number of specified breast cancer-related visits with either an oncologist or primary care physician ranged from 32.6\% (Ontario Year 2) to 84.4\% (NS Year 3). Underuse of surveillance breast imaging was identified in NS and BC. The proportion of patients receiving imaging for metastatic disease (not recommended in the guidelines) in BC, Manitoba, and Ontario (not reported in NS) ranged from 20.3\% (BC Year 5) to 53.3\% (Ontario Year 2). Compliance with recommended physician visits for patients with several chronic conditions was high in Ontario and NS. Preventive care was less than optimal in all provinces with available data.
\end{abstract}

Conclusions: Quality of breast cancer survivor follow-up care varies among provinces. Results point to exploration of factors affecting differences, province-specific opportunities for care improvement, and the value of administrative datasets for health system assessment.

Keywords: Breast cancer, Breast neoplasms, Primary care, Cancer survivors, Follow-up care, Survivorship care, Guideline-based care, Recommended care, Quality of care, Administrative databases

\footnotetext{
* Correspondence: mmcbride@bccrc.ca

${ }^{1}$ Cancer Control Research, BC Cancer, 675 West 10th Avenue, Room 2.107,

Vancouver, BC V5Z 1L3, Canada

${ }^{2}$ School of Population and Public Health, University of British Columbia,

Vancouver, Canada

Full list of author information is available at the end of the article
}

(c) The Author(s). 2019 Open Access This article is distributed under the terms of the Creative Commons Attribution 4.0 International License (http://creativecommons.org/licenses/by/4.0/), which permits unrestricted use, distribution, and reproduction in any medium, provided you give appropriate credit to the original author(s) and the source, provide a link to the Creative Commons license, and indicate if changes were made. The Creative Commons Public Domain Dedication waiver (http://creativecommons.org/publicdomain/zero/1.0/) applies to the data made available in this article, unless otherwise stated. 


\section{Background}

Breast cancer is the most common cancer in women worldwide. In 2012, nearly 1.7 million women were diagnosed with breast cancer and 6.2 million women had received a prior breast cancer diagnosis $[1,2]$. In countries such as Canada with advanced medical care, the five-year survival rate of early-stage breast cancers is $80-90 \%[1,2]$. However, survivors are at risk for late and ongoing problems including cancer recurrence [3, 4], second cancers [5-7], and physical and cognitive late effects of treatment [8-20], resulting in decreased quality of life [11, 12, 21, $22]$, higher disability, and mortality [9, 13, 14, 23-25]. In order to optimize cancer survivors' later health and quality of life, it is critical to deliver comprehensive and appropriate post-treatment care that includes general preventive care, surveillance for recurrences and new cancer, surveillance and management for late effects, and ongoing care for comorbidities [26, 27]. Guidelines for breast cancerrelated follow-up care were developed by the American Society for Clinical Oncology (ASCO) $[28,29]$ and Health Canada [30]. It appears that primary care physicians (PCPs) can provide safe follow-up care for early-stage breast cancer equivalent to oncologists [31], and that they can partner with community specialists in cancer-related follow-up [32], while also managing comorbidities and providing preventive care. However, access and use of guidelines for care, including care for cancer patients, has been variable among United States (US) [33-35] and Canadian physicians [36].

The amount of breast cancer post-treatment care delivered by PCPs differs by province in Canada [37], and underuse and overuse of guideline-based care has been identified in other countries [38, 39] and in two provinces [40] [41, 42]. The objective of this study was to assess and compare quality of post-treatment care in Canadian provinces by determining provincial variation in the level of compliance with guideline-based breast cancer-related survivor care, general preventive care, and ongoing care for comorbidities, using administrative datasets. We quantified and compared the extent of cancer follow-up, chronic and preventive care during survivorship, among four provinces that together represent $58 \%$ [43] of the Canadian population.

\section{Methods}

\section{Setting}

The study was conducted in the Canadian provinces of British Columbia (BC), Manitoba (MB), Ontario (ON), and Nova Scotia (NS). In Canada, "medically necessary" healthcare delivery for virtually all residents is the responsibility of provincial/territorial jurisdictions operating according to national legislated healthcare principles of public administration, comprehensiveness, universality, portability, and accessibility [44], resulting in jurisdictional variation in the scope and availability of specific services. Oncology treatment is provided through cancer centres (clinics) and hospitals. Community-based primary care providers (PCPs) and specialist physicians (accessed only through PCP referral) are typically paid using a "fee-forservice" model.

\section{Design}

This work was carried out as part of a Canadian study (Canadian Team to Improve Community-Based Cancer Care along the Continuum: "CanIMPACT") [45] aimed at improving integration and coordination of care by identifying gaps in care along the breast cancer care trajectory, from diagnosis to survivorship. This investigation tracked the healthcare of retrospective populationbased cohorts in each province using linked registries, and clinical and health administrative databases [46]. Detailed descriptions of data sources, linkages, and variables for the full cohorts [37, 46], and the survivorship study cohorts [47] have been previously published; a summary follows. This study was approved by all relevant research ethics boards and data access and privacy committees in each province. Consent was not required. Because of provincial confidentiality requirements, datasets were not able to be combined across provinces. Instead, parallel analyses were conducted in each province.

\section{Cohort identification and follow-up}

The original CanIMPACT cohorts consisted of all women aged 18 years and older diagnosed with incident invasive breast cancer (International Classification of Diseases Version 9: 174.x) from January 1, 2007 identified from each provincial cancer registry. Diagnosis years and follow-up varied according to data availability among provinces. For this study, women diagnosed to the end of 2012 (MB, ON, NS) or 2010 (BC), and alive at 30 months post-cancer diagnosis (to allow for a minimum of 1 year of survivorship care, as patients are censored 6 months before death) were identified. Of this group, women who did not have curative surgery, who had a new primary or recurrence diagnosed in the 27 months after their breast cancer diagnosis, who had metastases identified within 1 year of the breast cancer diagnosis, who did not link to the provincial healthcare insurance plan registries over the entire period from diagnosis date to their end date, or who had less than 1 year of survivorship follow-up were excluded. Women were also excluded if they did not have a valid individual health insurance number or were not residents of their home province at time of diagnosis, had a history of in situ breast cancer or any non-melanoma cancer, or had a histology other than a solid breast cancer [46].

Follow-up was complete to the end of 2013 in ON, 1 October 2013 in NS, end March 2015 in MB, and 
end 2011 in BC. The post-treatment "survivorship" phase of care was determined to start at 1 year post-diagnosis, continuing for up to 5 years from diagnosis to the end follow-up date, 6 months prior to death date, or 90 days before cancer recurrence or new primary cancer (identified from cancer registry data or billing claims for cancer treatment related to any of local recurrence, regional recurrence and distant metastasis, as indicated by subsequent radiation or surgery or a course of chemotherapy starting more than 2 years after diagnosis).

\section{Outcomes}

Adherence to the ASCO and Canadian cancer follow-up guidelines in effect during the study period $[28,30]$, guideline-based management of selected co-morbid illnesses, and recommended preventive care outcomes were evaluated. Overuse and underuse were considered. Level of adherence was assessed separately for Years 2-5 of follow-up for all those with full follow-up in that year.

Both ASCO and Canadian guidelines recommend regular physician visits for a medical history and physician examination. Both also advise a regular mammogram, and both recommend against additional tests or imaging in otherwise asymptomatic patients. The ASCO guideline did not recommend that follow-up be with a particular specialist, but did specify "medical oncologists, primary care providers, oncology nurses, (and) surgical oncologists" as some of their target practitioners [28, 29]. The Canadian guideline [30] recommended that responsibility for follow-up be formally allocated to a single physician (without identifying a specialty). All encounters were identified from billing claims records. Since follow-up care in Canada is carried out both by oncologists (defined in our study as radiation, medical, or surgical oncologists, and any surgeon conducting a breast surgery during the follow-up period) and PCPs, we measured visit adherence (number of physician visits) per follow-up year three ways, considering 1) oncologist and PCP visits; (2) oncologist visits only; and (3) breast cancer-related physician visits. For physician visits, adherence was defined as 3 to 4 visits in each of Years 2 and 3; and 2 visits in each of Years 4 and 5. In all provinces except NS, breast mammograms, ultrasounds, and medical resonance imaging (MRI) were classified as surveillance tests if they occurred more than 330 days from the date of the last such test, implying that they were not symptom-related. In NS, these tests were identified as "surveillance" based on procedure codes within the provincial breast screening database. Women with bilateral mastectomy were excluded from counts of surveillance mammograms. In assessing surveillance for recurrence, mammograms, breast ultrasounds and breast MRIs were counted; adherence was defined as one test per follow-up year. Surveillance for metastatic disease was evaluated by counting bone scans, chest imaging with chest $\mathrm{x}$-rays or chest computerized tomographic (CT) scans, abdomen/pelvic imaging with ultrasounds, CT scan, or non-breast-related MRI encounters. Adherence to guidelines for metastatic disease was defined as no surveillance investigations for bone scans, chest imaging with chest $\mathrm{x}$-rays, or chest computerized tomography (CT) scans, abdomen/pelvic imaging with ultrasounds, CT scan, or MRI - all investigations that may be used in the diagnosis of metastatic breast cancer but not recommended for routine surveillance in asymptomatic patients.

Adherence to population-based recommended preventive care and monitoring of common co-morbid chronic illnesses was assessed using published quality indicators $[33,35]$, and reported as adherent/not adherent. Preventive care assessment included examination of cervical and colon cancer screening, as well as bone densitometry. At least one cervical cancer screen for patients aged 20-69 during the entire follow-up period, with no previous cervical cancer, endometrial and ovarian cancer, and no hysterectomy history, was counted as adherence. Similarly, at least one bone densitometry during follow-up for women aged 65 years or older was considered adherence, and at least one colon cancer screening event for women aged 50-64 during follow-up was considered adherence. For chronic disease management we examined physician visits. Appropriate physician visit frequency for chronic stable angina, congestive heart failure, chronic obstructive pulmonary disease, and diabetes was defined as one visit every 6 months. One visit per year was considered appropriate for those with transient ischemic attack.

\section{Descriptive variables}

To assess comparability of the provincial cohorts, median age at diagnosis (with inter-quartile range), stage at diagnosis ("best stage" recorded in the cancer registries, converted to the TNM 6th edition staging system [48], and treatment received (categorized as lumpectomy, mastectomy, chemotherapy, and adjuvant radiotherapy), were determined. For the 6- to 30-month period prior to diagnosis (baseline), continuity of primary care (measured using the Usual Provider of Care (UPC) Index [49] was calculated. The UPC index was also calculated for PCP and medical oncology care at 1 year after the diagnosis date, at presumed end of primary treatment.

\section{Statistical analysis}

Descriptive statistics were used to characterize each provincial sample. For each provincial follow-up guideline, the frequency and proportion within each adherence category and follow-up year were determined. No statistical comparisons were conducted as these data represent a census experience (no sampling) and study power was 
high enough that small clinically unimportant differences were likely to be statistically significant.

\section{Results}

There were 9338 survivors from BC, 2688 from MB, 23, 700 from ON, and 2735 from NS (Table 1). The shorter median follow-up time in NS was related to an earlier end-of-study date than in other provinces [47]. MB and NS had higher proportions of early-stage (stages I and II) cancers; $\mathrm{BC}$ and $\mathrm{ON}$ had higher proportions of patients diagnosed with unknown stage. Initial treatment varied among provinces. A lower proportion of $\mathrm{BC}$ patients had lumpectomy procedures than the other provinces; a higher proportion of ON patients had mastectomies, a higher proportion of $\mathrm{BC}$ and $\mathrm{MB}$ patients underwent radiotherapy. An apparently lower proportion of $\mathrm{BC}$ patients received chemotherapy, but since $\mathrm{BC}$ did not collect chemotherapy data from those women not referred to a cancer centre, there are $14.5 \%$ of $\mathrm{BC}$ patients with no recorded chemotherapy status, which makes this assessment somewhat inaccurate. In the period prior to diagnosis, $42.3 \%$ of $\mathrm{BC}$ patients, $47.6 \%$ of $\mathrm{MB}$ patients, $56.2 \%$ of ON patients, and $58.7 \%$ of NS patients had high continuity of primary care (UPC). These proportions increased in the survivorship phase for $\mathrm{BC}$ and $\mathrm{MB}$, but remained stable for $\mathrm{ON}$ and NS (BC 51.4\%, MB 57.0\%, ON 56.9\%, NS 59.2\% for NS patients). BC had the highest proportion of patients with no medical oncologist visits in the survivorship phase $(57.8 \%$ versus a low of $20.6 \%$ in $\mathrm{ON}$ ) and a corresponding low proportion of patients with high medical oncology continuity of care $(16.8 \%$ versus a high of $38.9 \%$ in $\mathrm{ON}$ ).

\section{Adherence to guideline-based care}

Oncologist or primary care physician visits: For all provinces and in all follow-up years, the majority of survivors had more than the recommended number of patient visits to oncologists or PCPs (range 53.8\% in NS Year 3; 85.8\% in ON Year 4) (Fig. 1). The proportion of patients with fewer than the recommended number of visits (including 0 visits) ranged from 6.1\% (ON Year 2) to 29.7\% (NS Year 3).

Oncologist visits: Considerable inter-provincial variation in the proportion of survivors visiting an oncologist was observed, although all provinces showed a decrease in the proportion of survivors without an oncologist visit over time (Fig. 2a). In each follow-up year, BC had the lowest proportion of survivors with any oncologist visit (56.2\% Year 2; 29.8\% Year 5). MB and NS had similar oncologist visit rates (MB 75.5\% Year 2, 52.5\% Year 5; NS 78.7\% Year 2, 43.7\% Year 5). ON had the highest proportion of survivors who saw an oncologist annually $(91.7 \%$ Year 2, 74.8\% Year 5).

Breast cancer-related oncologist or primary care physician visits: When breast cancer was reported as the reason for visit, a much smaller proportion of patients had more than the recommended number of patient visits (range $4.1 \%$ in NS Year 3; 36.0\% in ON Year 4) (Fig. 2b). There were similar proportions of recommended, less than recommended, and greater than recommended visits in $\mathrm{BC}, \mathrm{MB}$, and $\mathrm{NS}$. ON had the highest proportion of visits consistent with recommendations (range 32.9\% Year 1 to $27.4 \%$ Year 4 ).

Surveillance breast imaging: For all provinces, the majority of survivors in each follow-up year received guideline-based surveillance imaging (Fig. 3a), with MB and $\mathrm{ON}$ reporting higher adherence than $\mathrm{BC}$ and NS. A greater proportion of survivors in NS received surveillance imaging in excess of guideline recommendations (between 9.1 and 20.7\%) compared to other provinces. In BC, a greater proportion of survivors received fewer imaging examinations than supported in the guidelines (between 43.7 and $50.2 \%$ ) compared to other provinces.

Imaging for metastatic disease: Routine imaging for metastatic disease is not recommended in surveillance of asymptomatic breast cancer patients. Between 20.3\% (BC, Year 5) and 53.3\% (ON, Year 2) of survivors did undergo imaging for metastatic cancer in the follow-up period (Fig. 3b). Considerable variation between provinces was observed, with adherence to this recommendation highest in $\mathrm{BC}$, and lowest in ON (NS data not available).

\section{Chronic disease management}

Prevalence of chronic stable angina ( 0.5 to $3.2 \%$ of provincial cohorts), congestive heart failure (1.0 to $1.6 \%$ ), chronic obstructive pulmonary disease (2.0 to $3.0 \%)$, transient ischemic attacks (0.4 to $0.8 \%$ ), and diabetes (9.8 to $11.5 \%$ ) was determined (Table 2). Small numbers meant that compliance with some guidelines was not measured in MB. High levels of compliance with physician visit recommendations for care of patients with any of these conditions were seen in ON (range 92.7-99.2\%) and NS (97.1-100\%), suggesting that these comorbidities were well managed among patients in these provinces. Much lower levels of compliance (range 6.0-30.6\%) were observed in BC.

\section{Preventive care}

Cervical cancer screening was recorded in $69.2 \%(B C)$, $67.0 \%(\mathrm{ON})$, and $74.7 \% \%(\mathrm{NS})$ of eligible women (Table 2; $\mathrm{MB}$ data not available). Bone densitometry was reported for $28.5 \%$ of women in BC, and $38.7 \%$ of those in ON (NS and MB data not available). Finally, $50.9 \%$ of age-eligible women in $\mathrm{BC}$ had colon cancer screening tests, and $45.9 \%$ of eligible $\mathrm{BC}$ women (NS and MB data not available).

\section{Discussion}

We conducted a population-based retrospective cohort study of four Canadian provinces that examined and compared the quality of care for breast cancer survivors within 
Table 1 Characteristics of Provincial Cohorts of Breast Cancer Survivors

\begin{tabular}{|c|c|c|c|c|}
\hline Variable & $B C$ & $\mathrm{MB}$ & ON & NS \\
\hline Overall N & 9338 & 2688 & 23,700 & 2735 \\
\hline Diagnosis years & $2007-2010$ & $2007-2012$ & $2007-2012$ & $2007-2012$ \\
\hline \multicolumn{5}{|l|}{ Follow-up Time (N,\%) } \\
\hline Median (Inter-quartile range) & $4(3-4)$ & $4(3-4)$ & $5(5-5)$ & $2(2-4)$ \\
\hline Full follow-up in Year 2 & $9338(100.0)$ & $2688(100.0)$ & $23,700(100.0)$ & $2735(100.0)$ \\
\hline Full follow-up in Year 3 & $8862(94.9)$ & $2583(96.1)$ & $22,297(94.1)$ & $2064(75.5)$ \\
\hline Full follow-up in Year 4 & $6213(66.5)$ & $2037(75.8)$ & $21,148(89.2)$ & $1726(63.1)$ \\
\hline Full follow-up in Year 5 & 3865 (41.4) & $1516(56.4)$ & $17,255(72.8)$ & $892(32.6)$ \\
\hline \multicolumn{5}{|l|}{ Age at Diagnosis, years } \\
\hline Median(Inter-quartile range) & $60(51-70)$ & $61(51-70)$ & $60(50-69)$ & $61(51-70)$ \\
\hline \multicolumn{5}{|l|}{ Stage at Diagnosis $(\mathrm{N}, \%)$} \\
\hline I & $4244(44.7)$ & $1268(47.2)$ & $10,036(42.3)$ & $\begin{array}{l}1366 \\
(50.0)\end{array}$ \\
\hline$\|$ & $3150(33.2)$ & $1086(40.4)$ & $8602(36.3)$ & $1010(36.9)$ \\
\hline III & $1089(11.5)$ & $317(11.8)$ & $2660(11.2)$ & $315(11.5)$ \\
\hline IV & $182(2.0)$ & $7(0.3)$ & $88(0.4)$ & $23(0.8)$ \\
\hline Unknown & $828(8.7)$ & $10(0.4)$ & $2314(9.8)$ & $21(0.8)$ \\
\hline \multicolumn{5}{|l|}{ Initial Treatment $(\mathrm{N}, \%)$} \\
\hline \multicolumn{5}{|l|}{ Lumpectomy } \\
\hline Yes & $4890(51.5)$ & $1948(72.5)$ & $17,275(72.9)$ & $1970(72.0)$ \\
\hline No & $4603(48.5)$ & $740(27.5)$ & $6425(27.1)$ & $765(28.0)$ \\
\hline \multicolumn{5}{|l|}{ Mastectomy } \\
\hline Yes & $3535(37.2)$ & $910(33.9)$ & $8293(35.0)$ & $1360(49.7)$ \\
\hline No & $5958(62.8)$ & $1778(66.1)$ & $15,407(65.0)$ & $1375(50.3)$ \\
\hline \multicolumn{5}{|l|}{ Chemotherapy } \\
\hline Yes & $3391(35.7)$ & $1244(46.3)$ & $10,884(45.9)$ & $1151(42.1)$ \\
\hline No & $4724(49.8)$ & $1444(53.7)$ & $12,816(54.1)$ & $1584(57.9)$ \\
\hline Unknown & $1378(14.5)$ & 0 & 0 & 0 \\
\hline \multicolumn{5}{|l|}{ Radiotherapy } \\
\hline Yes & $6079(64.0)$ & $1550(57.7)$ & $15,318(64.6)$ & $1559(57.0)$ \\
\hline No & $3414(36.0)$ & $1138(42.3)$ & $8382(35.4)$ & $1176(43.0)$ \\
\hline \multicolumn{5}{|l|}{ Baseline Continuity of Care $(\mathrm{N}, \%)$} \\
\hline 0 visit & $701(7.4)$ & $133(5.0)$ & $1448(6.1)$ & $93(3.4)$ \\
\hline $1-2$ visits & $1175(12.4)$ & $229(8.5)$ & $2514(10.6)$ & $333(12.2)$ \\
\hline UPC $<=0.75$ (Low) & $3605(38.0)$ & $1046(38.9)$ & $6414(27.1)$ & $70325.7)$ \\
\hline UPC > 0.75(High) & $4012(42.3)$ & $1280(47.6)$ & $13,324(56.2)$ & $1606(58.7)$ \\
\hline \multicolumn{5}{|c|}{ Survivorship PCP continuity of care $(\mathrm{N}, \%)$} \\
\hline 0 visit & $395(4.2)$ & $84(3.3)$ & $624(2.8)$ & $115(4.2)$ \\
\hline $1-2$ visits & $926(9.8)$ & $145(5.6)$ & $1470(6.6)$ & $413(15.1)$ \\
\hline UPC $<=0.75$ (Low) & $3289(34.7)$ & $883(34.2)$ & $7513(33.7)$ & $589(21.5)$ \\
\hline UPC > 0.75(High) & $4883(51.4)$ & $1471(57.0)$ & $12,690(56.9)$ & $1618(59.2)$ \\
\hline \multicolumn{5}{|c|}{ Survivorship Medical Oncologist continuity of care $(\mathrm{N}, \%)$} \\
\hline 0 visit & $5494(57.8)$ & $923(35.7)$ & $4603(20.6)$ & $829(30.3)$ \\
\hline $1-2$ visits & $1468(15.5)$ & $621(24.0)$ & $5066(22.7)$ & $1250(45.7)$ \\
\hline UPC $<=0.75$ (Low) & $945(10.0)$ & $345(13.4)$ & $3960(17.8)$ & $71(2.6)$ \\
\hline UPC > 0.75(High) & $1592(16.8)$ & $694(26.9)$ & 8668 (38.9) & $585(21.4)$ \\
\hline
\end{tabular}




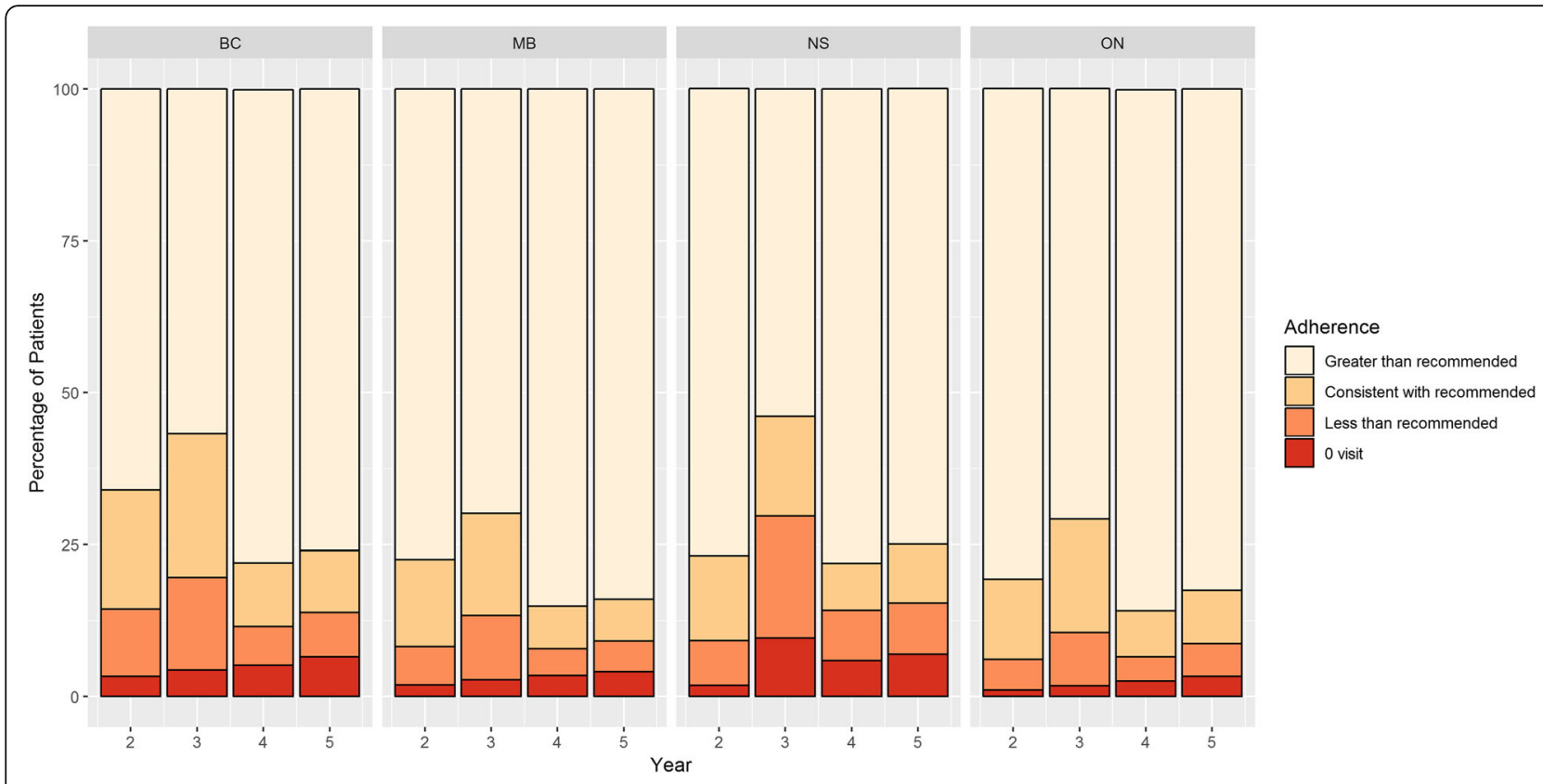

Fig. 1 Visit Adherence (PCP or Oncology)

a publicly-funded, comprehensive healthcare framework covering virtually all residents. We found considerable provincial variation in levels of reported guideline-based follow-up care, chronic disease management, and preventive care. These differences suggest that there may be both overuse and gaps in care at different points in the system and to a variable extent among provinces, which could indicate province-specific opportunities for care improvement. For instance, differences in continuity of medical oncologist visits may be related to differences in provincial organization of cancer care and cancer discharge policies. The results for oncologist follow-up visits are consistent with the fact that $\mathrm{BC}$ supports early discharge while $\mathrm{ON}$ tends to retain cancer patients longer in its cancer centres [47]. The resulting difference in type of follow-up physician may, in part, account for the observed variation in adherence to guideline-based surveillance imaging and preventive care. The results also suggest there may be access issues such as physician ability to obtain guidelines [36], and geographic availability of PCPs, oncologists, and services such as imaging equipment. Lack of a PCP is a particular concern. In 2016, approximately $12 \%$ of Canadian women aged 12 and older reported that they did not have a regular medical doctor or other healthcare provider [50]. The small amount of overuse of surveillance imaging in $\mathrm{BC}, \mathrm{MB}$ and $\mathrm{ON}$ (Fig. 3a) may be a result of too restrictive definition of an eligible test in our study (imaging only considered "surveillance" if $>330$ days from last such test), as other $\mathrm{ON}$ studies reported multiple surveillance tests in Year 2 post-treatment [41, 42]. In NS, a different approach was utilized based on availability of screening imaging event data in the provincial screening database, which would account for the higher proportion of patients reported to have received surveillance imaging in excess of guideline recommendations.

Similar to one Dutch study that included all adult-aged women [51], but in contrast to another Dutch study measuring hospital follow-up [52], in our study more women had more than the recommended number of visits to either oncologists or PCPs. However, the trend over time differed. In the Dutch study [51], women had less than the recommended frequency of surveillance mammography; among our study patients, receipt of surveillance mammography was generally consistent with guidelines, but a sizeable minority also had fewer than recommended surveillance mammograms.

Our results may also be affected by jurisdictional differences and misclassification in identifying patient eligibility, completeness of data collection, or incomplete or biased capture of events due to limitations in the definition of outcomes or differences in data sources. For instance, end of primary treatment date was not available in all provinces, so could not be used as the definition of the start of follow-up. We chose a date that we felt would provide high confidence that all patients meeting the survivor criteria (including undergoing primary surgery, with no recorded new primary cancer, recurrence, or metastases at 1 year post-diagnosis) would be in the follow-up phase of care. MRI encounters were not captured in BC since MRI facilities are facility-funded, rather than fee-for-service. In our study, a yearly MRI or ultrasound on its own was considered as adherence to 


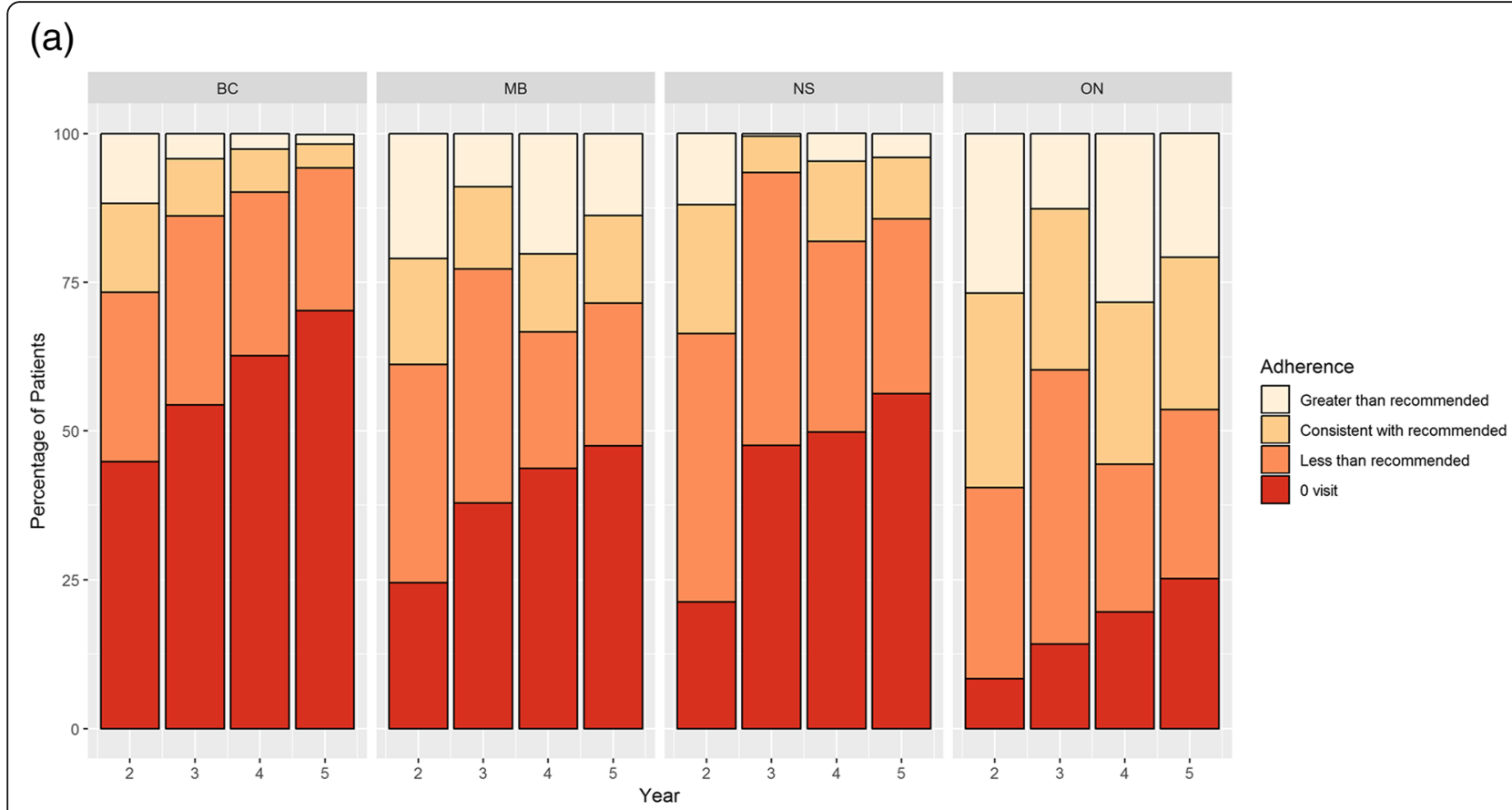

(b)

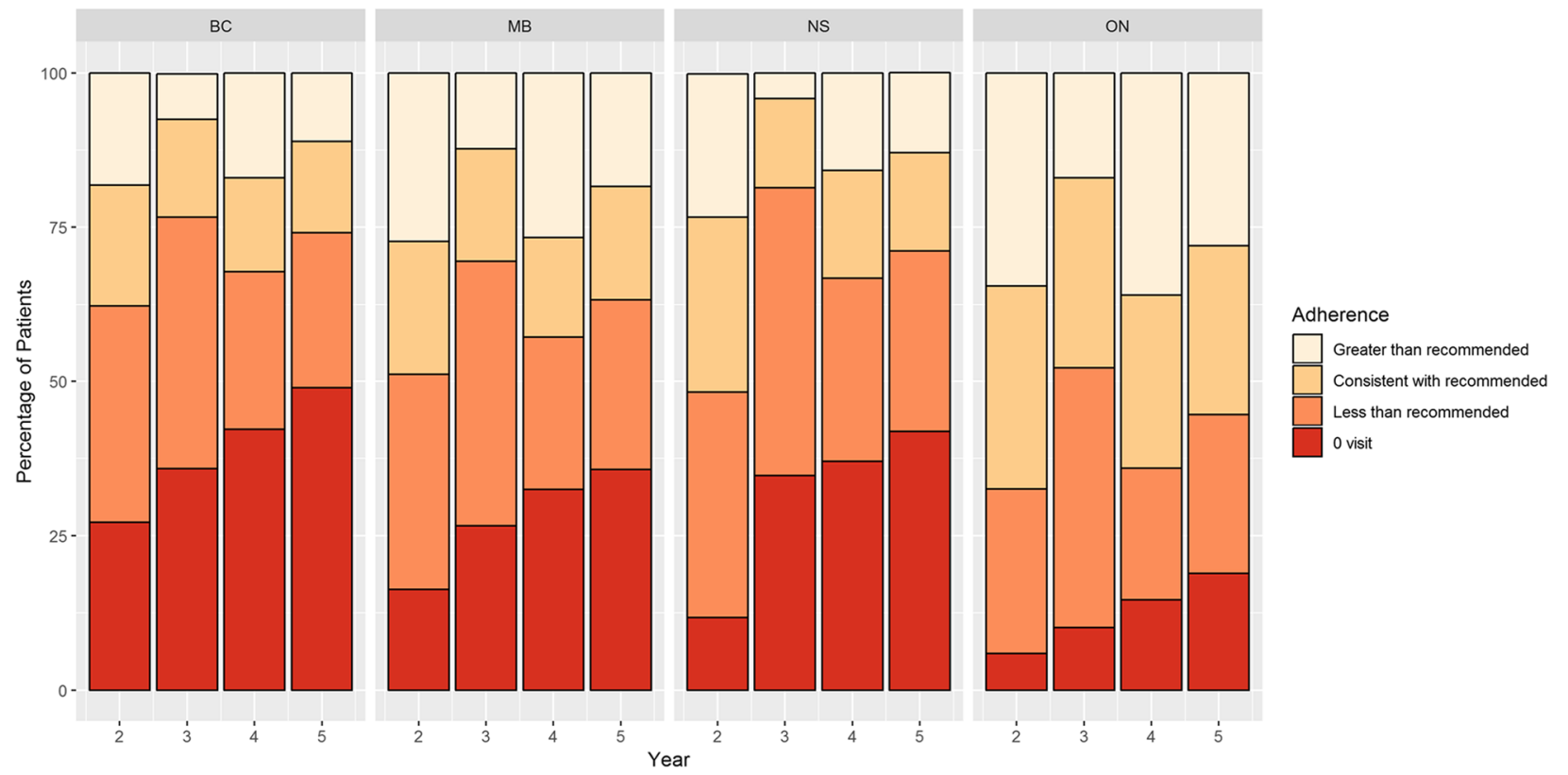

Fig. 2 a Oncologist Visit Adherence. b Breast cancer-related PCP or Oncology Adherence

surveillance. However, a common clinical scenario is a surveillance mammogram that identifies something suspicious and recommends more imaging (perhaps by MRI or ultrasound) which then resolves the issue as being benign. Counting those imaging events is probably not appropriate, since they are not surveillance-based; however, since indications for imaging were not available, these could not be excluded. Similarly, the differences in adherence to chronic disease care in $\mathrm{BC}$ may be a result of incomplete recording of these activities as reasons for visits. The decrease in overuse of surveillance imaging from Year 2 to Year 5 in NS compared to other provinces may be an artefact of coding quality issues in earlier years of the NS Breast Cancer Screening Program database rather than clinical practice.

The findings presented in this study are based on outpatient healthcare administrative data over several years among geographically-defined populations in several 


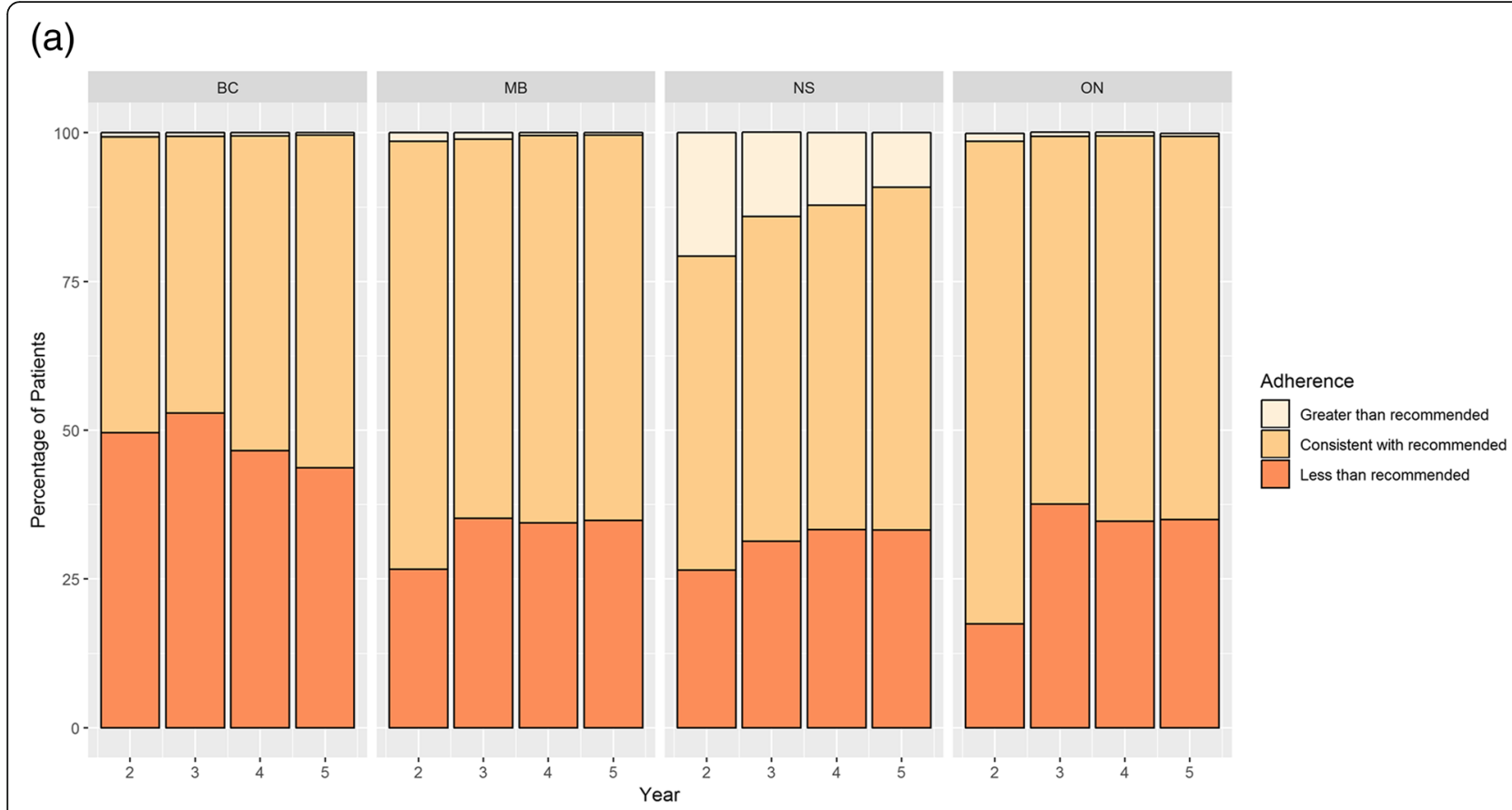

(b)
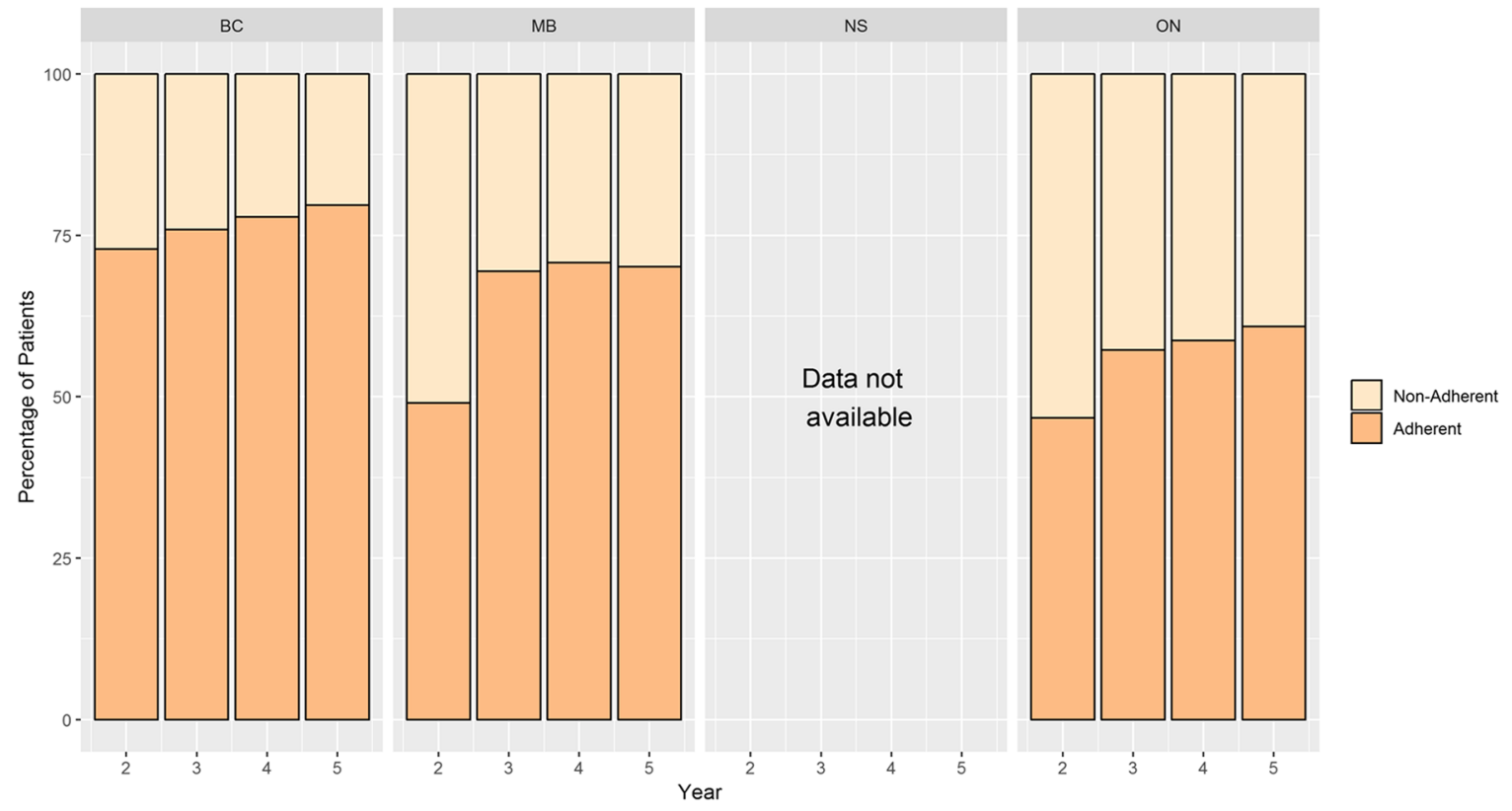

Fig. 3 a Surveillance Breast Imaging. b Imaging for Metastatic Disease

jurisdictions with the same healthcare framework but differences in approaches to healthcare delivery. Administrative data can provide more accurate estimates of medical care than alternative approaches based on more indirect data sources, and have been used to examine follow-up care among older breast cancer survivors in the US [53] and those within a large integrated healthcare system [54]. The comparative analysis of these data permits direct assessment of the relative performance across provinces in delivery of guideline-based care at the population level in the first 5 years post-treatment, when surveillance is most intensive [55]. Although results are generated from the Canadian health system, they do provide real-world data in a total geographicallydefined adult breast cancer population, compared to US Medicare, which includes only women 65 years and over plus some at-risk subgroups; and healthcare systems that do not cover entire population of a specific area. 
Table 2 Prevalence and adherence for chronic diseases and preventive care

\begin{tabular}{|c|c|c|c|c|}
\hline & $B C$ & $\mathrm{MB}$ & ON & NS \\
\hline Overall $N$ with chronic disease and/or preventive care & 8862 & 2583 & 22,297 & 2735 \\
\hline Diagnosis years & $2007-2010$ & $2007-2011$ & $2007-2010$ & 2007-2012 \\
\hline \multicolumn{5}{|l|}{ Prevalence for Chronic Disease ( $\mathrm{N}, \%)$} \\
\hline Chronic Stable Angina (CSA) & $283(3.2)$ & $24(0.9)$ & $572(2.6)$ & $14(0.5)$ \\
\hline Congestive Heart Failure (CHF) & $143(1.6)$ & $26(1.0)$ & $239(1.1)$ & $35(1.3)$ \\
\hline Chronic Obstructive Pulmonary Disease (COPD) & $228(2.6)$ & $53(2.1)$ & $437(2.0)$ & $82(3.0)$ \\
\hline Transient Ischemic Attack (TIA) & $55(0.6)$ & $21(0.8)$ & $124(0.6)$ & $11(0.4)$ \\
\hline Diabetes (DM) & $1022(11.5)$ & $255(9.9)$ & $2189(9.8)$ & $310(11.3)$ \\
\hline \multicolumn{5}{|l|}{ Adherence to Chronic Disease Indicators (\%) } \\
\hline CSA: 6-month Visits & 6.0 & - & 95.6 & 100 \\
\hline CHF: 6-month Visits & 23.8 & - & 92.9 & 97.1 \\
\hline COPD: 6-month Visits & 9.2 & - & 92.7 & 98.8 \\
\hline TIA: 1-year Visits & 14.5 & - & 99.2 & 100 \\
\hline DM: 6-month Visits & 30.6 & 99.6 & 95.8 & 97.4 \\
\hline \multicolumn{5}{|l|}{ Prevalence for Preventive Care (N, \%) } \\
\hline Cervical cancer screening & $6573(69.2)$ & - & $14,934(67.0)$ & $2036(74.7)$ \\
\hline Bone densitometry & 2705 (28.5) & - & $8625(38.7)$ & - \\
\hline Colorectal cancer screening & $4833(50.9)$ & - & $10,233(45.9)$ & - \\
\hline
\end{tabular}

However, there are some limitations to the study. Followup time and case retention varied among the provinces, introducing some error. Data comparability was affected due to provincial differences in the scope of care provided and recording of events. For some surveillance measures, we could not always separate out tests that may have been for symptoms or new findings on physical examination. Importantly, these results do not provide any direct information about the reasons for the observed differences in care. In order to inform care improvement, an assessment of sociodemographic, clinical, healthcare delivery, and system factors that drive these differences, is needed. In addition, the perspectives of healthcare managers, oncologists, FPs and survivors about barriers and facilitators of quality care uptake are required, to guide future strategies and interventions to improve care delivery. Lastly, there are additional challenges of data availability, completeness, comparability and quality that make such comparative studies more challenging across different healthcare systems $[55,56]$.

\section{Conclusions}

This study found deficiencies and inefficiencies in followup care for breast cancer survivors, and differences between provinces within the Canadian healthcare system. Further study is needed to identify modifiable factors in order to improve follow-up care of breast cancer survivors by primary care providers. This investigation demonstrates the value of registries and healthcare administrative datasets in assessing the quality of healthcare. However, further work is needed to improve comparability of such data across jurisdictions.

\section{Abbreviations}

ASCO: American Society for Clinical Oncology; BC: British Columbia; CanIMPACT: Canadian Team to Improve Community-Based Cancer Care along the Continuum; CHF: Congestive Heart Failure; COPD: Chronic Obstructive Pulmonary Disease; CSA: Chronic Stable Angina;

CT: Computerized tomography; DM: Diabetes; MB: Manitoba; MRI: Medical resonance imaging; NS: Nova Scotia; ON: Ontario; PCP: Primary care physicians; TIA: Transient Ischemic Attack; UPC: Usual Provider of Care; US: United States

\section{Acknowledgements}

The authors thank Robin Urquhart and Geoff Porter, Dalhousie University, Halifax, Nova Scotia, and Donna Turner, CancerCare Manitoba, Winnipeg, Manitoba, for additional data interpretation. Data for this study were provided by Population Data BC and BC Cancer. All inferences, opinions, and conclusions drawn in this study are those of the authors, and do not reflect the opinions or policies of the British Columbia Data Stewards [57-59]. This study was approved by the University of Manitoba's Health Research Ethics Board and Manitoba Health's Health Information and Privacy Committee. We gratefully acknowledge CancerCare Manitoba for their ongoing support and Manitoba Health for the provision of data. The results and conclusions presented are those of the authors. No official endorsement by Manitoba Health is intended or should be inferred. This study was supported by the Institute for Clinical Evaluative Sciences, which is funded by an annual grant from the Ontario Ministry of Health and Long-Term Care (MOHLTC). The opinions, results and conclusions reported in this paper are those of the authors and are independent from the funding sources. No endorsement by the Institute for Clinical Evaluative

Sciences or the Ontario MOHLTC is intended or should be inferred. Parts of this material are based on data and information provided by Cancer Care Ontario (CCO). The opinions, results, views, and conclusions reported here are those of the authors and do not necessarily reflect those of CCO. No endorsement by CCO is intended or should be inferred. Portions of the data used in this report were made available by Health Data Nova Scotia of Dalhousie University and the Nova Scotia Department of Health and Wellness. However, the observations and opinions expressed are those of the authors and do not represent those of either Health Data Nova Scotia or the Department of Health and Wellness.

\section{Authors' contributions}

PAG and MLM took primary responsibility for the design of the study. MLM took primary responsibility for $\mathrm{BC}$ data acquisition, the interpretation of data, and drafting and revising the article. She gave final approval of the version 
to be published. PAG, KD and CK provided advice and direction for the study design, took primary responsibility for $\mathrm{ON}, \mathrm{MB}$, and NS data acquisition, contributed to data interpretation, revised the article critically for important intellectual content, and gave final approval of the version to be published. $\mathrm{DL}, \mathrm{L}$, and MW provided advice and direction for the study design and contributed to data analysis and interpretation. They also gave final approval of the version to be published. All authors have read and approved the manuscript. EG provided advice and overall direction for study design, critical interpretation of the study, and gave final approval of the version to be published.

\section{Funding}

This study was funded by the Canadian Institutes of Health Research (CIHR) (grant 128272). The funding body played no role in the design of the study, the collection, analysis and interpretation of data, or in writing the manuscript.

\section{Availability of data and materials}

The data supporting the conclusions of this article are not available in a public repository, in accordance with provincial government policies. They are housed at Population Data BC (BC), Manitoba Population Research Data Repository (MB), Institute for Clinical Evaluative Sciences (ON), and Health Data Nova Scotia (NS).

\section{Ethics approval and consent to participate}

Ethics approvals were received by the BC Cancer-University of British Columbia Research Ethics Board in BC, the University of Manitoba Health Research Ethics Board in MB, the Health Sciences and Affiliated Hospitals Research Ethics Board at Queen's University in ON, and the Nova Scotia Health Authority Research Ethics Board in NS. Approvals for data access and use were obtained from all data stewards in each province. No consent was required for this analysis, as the research involved no more than minimal risk, the research did not involve an intervention, lack of consent was unlikely to adversely affect patient welfare, and it was impracticable to obtain consent.

\section{Consent for publication}

Not applicable.

\section{Competing interests}

The authors declare that they have no competing interests.

\section{Author details}

${ }^{1}$ Cancer Control Research, BC Cancer, 675 West 10th Avenue, Room 2.107, Vancouver, BC V5Z 1L3, Canada. ${ }^{2}$ School of Population and Public Health, University of British Columbia, Vancouver, Canada. ${ }^{3}$ Department of Public Health Sciences, Queen's University, Kingston, Canada. ${ }^{4}$ Cancer Research Institute, Queen's University, Kingston, Canada. ${ }^{5}$ Institute of Clinical Evaluative Sciences, Queen's University, Kingston, Canada. ${ }^{6}$ Department of Community Health Sciences, University of Manitoba, Winnipeg, Canada. ${ }^{7}$ Epidemiology and Cancer Registry, CancerCare Manitoba, Winnipeg, Canada. ${ }^{8}$ Cancer Outcomes Research Program, Dalhousie University and Nova Scotia Health Authority, Halifax, Canada. ${ }^{9}$ Critical Care Services Ontario, Toronto, Canada. ${ }^{10}$ Department of Family and Community Medicine, University of Toronto, Toronto, Canada. ${ }^{11}$ Dalla Lana School of Public Health, University of Toronto, Toronto, Canada. ${ }^{12}$ Ontario Institute for Cancer Research, Toronto, ON, Canada.

Received: 11 February 2019 Accepted: 26 June 2019

Published online: 04 July 2019

\section{References}

1. WCRF. Breast cancer statistics. 2019 (cited 2 July 2019). https://www.wcrf. org/dietandcancer/cancer-trends/breast-cancer-statistics.

2. WCO. Cancer fact sheets. 2019 (cited 2 July 2019). http://gco.iarc.fr/today/ fact-sheets-cancers.

3. Bardia A, Arieas ET, Zhang Z, Defilippis A, Tarpinian K, Jeter S, Nguyen A, Henry NL, Flockhart DA. Comparison of breast cancer recurrence risk and cardiovascular disease incidence risk among postmenopausal women with breast cancer. Breast Cancer Res Treat. 2012;131(3):8.

4. Pan $\mathrm{H}$, et al. 20-year risks of breast-Cancer recurrence after stopping endocrine therapy at 5 years. N Engl J Med. 2017;377:11.

5. Curtis RE, et al. Risk of leukemia after chemotherapy and radiation treatment for breast cancer. N Engl J Med. 1992;326(26):7.
6. Schaapveld MV, O; Louwman MJ. Risk of new primary nonbreast cancers after breast cancer treatment: a Dutch population-based study. J Clin Oncol. 2008;26(8):8.

7. Kurian A, et al. Second primary breast Cancr occurrence according to hormone receptor status. J Natl Cancer Inst. 2009;101(15):8.

8. Bird BR, Swain SM. Cardiac toxicity in breast cancer survivors: Review of potential cardiac problems. Clin Cancer Res. 2008;14(1):11.

9. Patnaik JL, Byers T, DiGuiseppi C, Dabelea D, Denberg TD. Cardiovascular disease competes with breast cancer as the leading cause of death for older females diagnosed with breast cancer: a retrospective cohort study. Breast Cancer Res. 2011;13(3):1.

10. Abdel-Razeq H, Awidi A. Bone health in breast cancer survivors. J Cancer Res Ther. 2011;7(3):8.

11. Brunault P, Toledano A, Aguerre C, Suzanne I, Garaud P, Trzepidur-Edom M, Calais G, Camus V. Impact of late treatment-related radiotherapy toxicity, depression and anxiety on quality of life in long-term breast cancer survivors. Bull Cancer. 2012;99(5):10.

12. Reyes-Gibby CC, Anderson KO, Morrow PK, Shete S, Hassan S. Depressive symptoms and health-related quality of life in breast cancer survivors. $J$ Women's Health. 2011;21(3):8.

13. Erickson VS, Pearson ML, Ganz PA, Adams J, Kahn KL. Arm edema in breast cancer patients. J Natl Cancer Inst. 2001;93(2):11.

14. Paci E, Cariddi A, Barchielli A, Bianchi S, Cardona G, Distante V, Giorgi D, Pacini P, Zappa M, Del Turco MR. Long-term sequelae of breast cancer surgery. Tumori. 1996;82(4):4.

15. Wefel JS, Kesler SR, Noll KR, Schagen SB. Clinical characteristics, pathophysiology, and management of noncentral nervous system cancerrelated cognitive impairment in adults. CA Cancer J Clin. 2015;65(2):6.

16. Martel $\mathrm{S}$, et al. Breast cancer treatment-induced cardiotoxicity. Expert Opin Drug Saf. 2017;16(9):18.

17. Bruyère $\mathrm{O}$, et al. Skeletal health in breast cancer survivors. Maturitas. 2017;105(Nov):5.

18. Hsu T, et al. Quality of life in long-term breast Cancer survivors. JCO. 2013;31:9.

19. Koch $L$, et al. Quality of life in long-term breast cancer survivors - a 10-year longitudinal population-based study. Acta Oncol. 2013;52(6):10.

20. Ewertz $M$, Jensen A. Late effects of breast cancer treatment and potentials for rehabilitation. Acta Oncol. 2011;50(2):7.

21. Knobf MT. The influence of endocrine effects of adjuvant therapy on quality of life outcomes in younger breast cancer survivors. Oncologist. 2006;11(2):15.

22. Stricker C. Endocrine effects of breast Cancer treatment. Semin Oncol Nurs. 2007:23(1):16.

23. Ahern TP, Lash TL, Thwin SS, Silliman RA. Impact of Acquired Comorbidities on All-Cause Mortality Rates Among Older Breast Cancer Survivors. Med Care. 2009;47(1):7.

24. Louwen W, Klokman W, Coebergh J. Excess mortality from breast cancer 20 years after diagnosis when life expectancy is normal. $\mathrm{Br} J$ Cancer. 2001;84(5):4.

25. Janssen-Heijnen $M$, et al. Small but significant excess mortality compared with the general population for long-term survivors of breast cancer in the Netherlands. Ann Oncol. 2014;25(1):5.

26. Hewitt M, Greenfield S, Stovall E. From Cancer patient to Cancer survivor: lost in transition. Washington DC: National Academies Press; 2006.

27. Fu MR, Axelrod D, Guth AA, Cleland CM, Ryan CE, Weaver KR, Qiu JM, Kleinman R, Scagliola J, Palamar JJ, D'Eramo Melkus G. Comorbidities and Quality of Life among Breast Cancer Survivors: A Prospective Study. J Pers Med. 2015;5(3):229.

28. Khatcheressian JL, Wolff, AC, Smith TJ, Grunfeld E, Muss HB, ogel VG, Halberg F, Somerfield MR, Davidson NE. American Society of Clinical Oncology 2006 update of the breast cancer follow-up and management guidelines in the adjuvant setting. JCO. 2006;24(31):7.

29. Khatcheressian JL, Hurley P, Bantug E, Esserman L, Grunfeld E, Halberg F, Hantel A, Henry NL, Muss HB, Smith TJ, Vogel VG, Wolff AC, Somerfield MR, Davidson NE. Breast Cancer Follow-Up and Management After Primary Treatment: American Society of Clinical Oncology Clinical Practice Guideline Update. J Clin Oncol. 2013;31(7):5.

30. Grunfeld E, Dhesy-Thind S, Levine M. Clinical practice guidelines for the care and treatment of breast cancer: follow-up after treatment for breast cancer (summary of the 2005 update). CMAJ. 2005;172(10):2.

31. Grunfeld E, Levine MN, Julian JA, Coyle D, Szechtman B, Mirsky D, Verma S, Dent S, Sawka C, Pritchard Kl, Ginsburg D, Wood M, Whelan T. Randomized 
Trial of Long-Term Follow-Up for Early-Stage Breast Cancer: A Comparison of Family Physician Versus Specialist Care. J Clin Oncol. 2006;24(1):8.

32. Rubin $\mathrm{G}$, et al. The expanding role of primary care in cancer control. Lancet Oncol. 2015;16(12):1231-72.

33. Asch SM, Sloss EM, Hogan C, Brook RH, Kravitz RL. Measuring Underuse of Necessary Care Among Elderly Medicare Beneficiaries Using Inpatient and Outpatient Claims. JAMA. 2000;284(18):9.

34. Elston Lafata J, Simpkins J, Schultz L, Chase GA, Johnson CC, Yood MU, Lamerato L, Nathanson D, Cooper G. Routine Surveillance Care After Cancer Treatment With Curative Intent. Med Care. 2005;43(6):8.

35. Earle CC, Neville BA. Under Use of Necessary Care among Cancer Survivors. Cancer. 2004;101(8):8.

36. Sahota IS, Kostaras X, Hagen NA. Improving access to cancer guidelines: feedback from health care professionals. Curr Oncol. 2015;22(6):7.

37. Jiang $L$, et al. Primary care physician use across the breast cancer care continuum: CanIMPACT study using Canadian administrative data. Can Fam Physician. 2016;62(10):e589-98.

38. Hahn R, Kasd M. Determinants of sustainability reporting: A review of results, trends, theory, and opportunities in an expanding field of research. J Clean Prod. 2013;59(1):17.

39. Chopra I, Chopra A. Follow-up care for breast cancer survivors: improving patient outcomes. Patient Relat Outcome Meas. 2014;5:15.

40. Urquhart R, Lethbridge L, Porter G. Patterns of cancer Centre follow-up care for survivors of breast, colorectal, gynecologic, and prostate cancer. Curr Oncol. 2017;24(6):7.

41. Grunfeld $E$, et al. Population-based longitudinal study of follow-up care for breast cancer survivors. J Oncol Pract. 2010;6(4):174-81.

42. Enright K, Desai T, Sutradhar R, Gonzalez A, Powis M, Taback N, Booth CM, Trudeau ME, Krzyzanowska MK. Factors associated with imaging in patients with early breast cancer after initial treatment. Curr Oncol. 2018;25(2):7.

43. Statistics Canada. Population estimates on July 1st, by age and sex. 2017 [cited 2017 September 7]; Available from: http://www.statcan.gc.ca/tablestableaux/sum-som/101/cst01/demo02a-eng.htm.

44. Madore O. The Canada health act: overview and options. Ottawa: Ottawa Library of Parliament, Parliamentary Research Branch; 2003. Available from http://publications.gc.ca/site/eng/52129/publication.html.

45. Grunfeld, E. Welcome to the CanIMPACT: Canadian team to improve community-based Cancer care along the continuum website. 2018 [cited 2018 February 6]; Available from: http://www.canimpact. utoronto.ca.

46. Groome PA, ML MB, Jiang L, Kendell C, Decker KM, Grunfeld E, Krzyzanowska MK, Winget M. Lessons Learned: It Takes a Village to Understand Inter-Sectoral Care Using Administrative Data across Jurisdictions. IJPDL. 2018;3(3):12.

47. Kendell C, Decker KM, Groome PA, McBride ML, Jiang L, Krzyzanowska MK, Porter G, Turner D, Urquhart R, Winget M, Grunfeld E. Use of physician services during the survivorship phase: a multi-province study of women diagnosed with breast cancer. Curr Oncol. 2017;24(2):81-9.

48. Wittekind C, Asamura H, Sobin LH. TNM Atlas, 6th Edition. 6 ed: WileyBlackwell; 2014. p. 408

49. Pollack CE, Hussey PS, Rudin RS, Fox DS, Lai J, Schneider EC. Measuring Care Continuity: A Comparison of Claims-Based Methods. Med Care. 2016;54(5):19.

50. Statistics Canada. Primary Health Care Providers. 2016. 2017 [cited 2018 June 6]; Available from: https://www150.statcan.gc.ca/n1/pub/82-625-x/ 2017001/article/54863-eng.htm.

51. Grandjean I, et al. Evaluation of the adherence to follow-up care guidelines for women with breast cancer. Eur J Oncol Nurs. 2012;16(3):5.

52. Lu W, et al. Underuse of long-term routine hospital follow-up care in patients with a history of breast cancer? BMC Cancer. 2011;11:7.

53. Lash TL, Fox MP, Buist DSM, Wei F, Field TS, Frost FJ, Geiger AM, Quinn VP, Yood MU, Silliman RA. Mammography Surveillance and Mortality in Older Breast Cancer Survivors. J Clin Oncol. 2007;25(21):6.

54. Cooper GS, Schultz L, Simpkins J, Lafata JE. The Utility of Administrative Data for Measuring Adherence to Cancer Surveillance Care Guidelines. Med Care. 2007:45(1):7.

55. Lipscomb J, Yabroff KR, Hornbrook MC, Gigli A, Francisci S, Krahn M, Gatta G, Trama A, Ritzwoller DP, Durand-Zaleski I, Salloum R, Chawla N, Angiolin C, Crocetti E, Giusti F, Guzzinati S, Mezzetti M, Miccinesi G, Mariotto A. Comparing Cancer Care, Outcomes, and Costs Across Health Systems: Charting the Course. J Natl Cancer Inst. 2013;46(1):7.
56. Groene $\mathrm{O}$, et al. Feasibility of using administrative data to compare hospital performance in the EU. Int J Qual Health Care. 2014;26(S1):8.

57. BC Cancer Agency, editor. BC Cancer Agency registry data (2011), BC Cancer Agency, Editor: Population Data BC; 2011

58. British Columbia Ministry of Health. Medical Services Plan (MSP) Payment Information File, MOH, Editor: Population Data BC; 2011.

59. British Columbia Ministry of Health. Consolidation File (MSP Registration \& Premium Billing), MOH, Editor: Population Data BC; 2011.

\section{Publisher's Note}

Springer Nature remains neutral with regard to jurisdictional claims in published maps and institutional affiliations.
Ready to submit your research? Choose BMC and benefit from:

- fast, convenient online submission

- thorough peer review by experienced researchers in your field

- rapid publication on acceptance

- support for research data, including large and complex data types

- gold Open Access which fosters wider collaboration and increased citations

- maximum visibility for your research: over $100 \mathrm{M}$ website views per year

At $\mathrm{BMC}$, research is always in progress.

Learn more biomedcentral.com/submissions 